Original Research Paper

\title{
Media Identity in Structure of Personality: Formation and Typology
}

\author{
${ }^{1}$ Igor Nikolaevich Blokhin, ${ }^{2}$ Sergey Nikolaevich Ilchenko and ${ }^{3}$ Lyudmila Petrovna Shesterkina \\ ${ }^{1}$ Department of Theory of Journalism and Mass Communication, Saint Petersburg State University, St. Petersburg, Russia \\ ${ }^{2}$ Department of TV and Radio Journalism, Saint Petersburg State University, St. Petersburg, Russia \\ ${ }^{3}$ Department of media, South Ural State University, Chelyabinsk, Russia
}

\author{
Article history \\ Received: 11-04-2016 \\ Revised: 21-04-2016 \\ Accepted: 27-05-2016 \\ Corresponding Author: \\ Igor Nikolaevich Blokhin, \\ Department of Theory of \\ Journalism and Mass \\ Communication, Saint \\ Petersburg State University, St. \\ Petersburg, Russia \\ Tel: (+7)921-949-76-34 \\ E-mail: igor.blohin@mail.ru \\ i.blokhin@spbu.ru
}

\begin{abstract}
The study provides the analysis of different approaches to determining media identity. This phenomenon is substantiated in the context of media landscape as a complex of relationships and communicative actions of a personality within the media system. The role of social relations in the processes of building the structure of personality is considered together with anthropological, sociological and psychological peculiarities of identity. Significance of media landscape in creating media identity representing the result of building the personality's structure as an agent in the media landscape has been determined. Specific features and factors of forming media identity in the process of socialization have been established. The task is set to determine the nature of interrelations between identity and communicative action. The forms of media identity manifestation are studied; the typology of the phenomenon is suggested based on the types of communicative actions. The types of media landscape agents and, consequently, the types of media identities are analyzed. Specific features of creating media identities among secondary school students in the network environment affected by factors of multimedia, hypertextuality and interactivity have been identified. In the process of developing individuality of a young person, the significance of media landscape is stipulated by the accessibility of education and cultural values, by the openness of organizations and territories. Under conditions when the media predetermine the structures of social environment, there is an ever growing importance of journalists who immerse even deeper in the processes of regulating communications and media landscape navigation. The role of journalists' education and their competence in acting as operators and propagators of information and knowledge becomes more important. Social competences and their development determine the degree of people's awareness in contacts with social environment.
\end{abstract}

Keywords: Media Identity, Identity, Communicative Action, Media Education, Media Competence, Media Landscape

\section{Introduction}

A modern person exists in a convergent synthetic world of social relationships, communicative actions and media activity. Different types and means of human actions and behavior create multiple establishments (institutions, organizations, environments, spheres, fields) that together make the integral structures possessing the nature of space or landscape. Applying the idea of "landscape" for describing and analyzing social (social landscape) and media (media landscape) systems suggests that the categories of spatial coordinates should be used here together with such relevant coordinates as reference points that make it possible to implement the procedures of modeling and measuring. Human personality, as a subject of system building, concentrates at those reference points the values according to which it does one's own actions in 
space and estimates the actions of other people. This ability to conceive (to determine, to characterize, to describe, to justify, to substantiate, etc) and to correlate (to compare, to evaluate) oneself with other people makes the basis of identity.

Media landscape as a part of human environment is formed by the experience of communicative action, effected by means of communication. However, by contrast to social environment, here the role of communicative freedom within the range of possible role behavior patterns is much more important. The existence limited by the environment of media landscape predetermines the formation of "media identity" as the ability to conceive oneself as an agent in the media landscape and to correlate one's own communicative actions with the actions of other agents.

Media landscape makes it possible for a person to reveal oneself as an independent (integral) subject (actor) and this possibility predetermines its attractiveness for a personality. In this case, the attitude toward a person is changed; he/she represents the center of his/her own system of values and world outlook. A person is understood in the media landscape through the information he/she consumes, through the information he/she responds to, through the communication he/she joins, initiates or provokes. The essence of human behavior can be judged by the intensity of his/her activity and by the patterns of his/her role behavior in media landscape. The types of role behavior patterns of a personality in media landscape are determined by the forms of communicative action that also determine the types of media identity.

The secondary school graduates of the last decade are the first generation whose conscious experience began with the era of the widespread new media. Those people are the most active Internet users; they create media of their own and use the existing ones very actively; considerable part of media messages is addressed to them, they are exactly the people who will predetermine the development of media in the nearest future. Those circumstances were the reasons for the attention that the researches paid to the graduates of secondary schools as to the generation in which the significance of media personality is actualized.

Presently, discussions are underway to identify the role and the place of school in developing media competences of the pupils. UNESCO holds specifically dedicated conferences and develops special programs on this issue; therefore, the analysis of the available media education practices in school and the evaluation of media competences among the school students who graduate under the conditions when no special programs are present in their curriculum is a critical task. The discussion should also cover the development of the upgraded theoretical basis reconsidering the leading concepts of the last century.

\section{Literature Review}

\section{Identity}

Sociologically understood, identity is the characteristic of a person related to his/her belonging to some certain group. The expression of this belonging is predetermined by the status and is revealed through the performance of a social role. In psychology, identity is defined as a will of an individual to remain forever oneself under changing circumstances and is the result of perceiving one's own self as a personality different from other people. Eric Ericson introduced the idea of "egoidentity", of a personality's integrity, of its oneness and continuity notwithstanding the changes that occur in the course of a man's growth and development-it is "the awareness of the fact that there is a self-sameness and continuity to the ego's synthesizing methods and a continuity of one's meaning for others" (Ericson, 2006). The loss of ego-identity leads to identity crisis when the integrity, the oneness and the belief in one's own social role either decrease or disappear.

The ways of building the structure of personality represent conceptual justification of the fact that within the essence of a human being there is always a nonsocial element of his own. Sigmund Freud used to highlight the controversies existing between the conscious rational "Ego", the obligation-based regulatory "Super-Ego" and the unconscious instinctive "Id". William James believes that within the structure of personality (empirical "Me" self that a person identifies as "one's own") there are material, social and spiritual components (James, 1991). A metaphor of a mirror was used by Cooley (2000) who proposed the concept of the looking glass self, according to which a personality represents a sum of psychological reactions, such as "the idea of how others perceive us; the idea of how others assess this image of ours and some certain perception of oneself such as pride or shame".

\section{Identity and Communicative Action}

Human reaction has a communicative expression; its consequence is represented by social communicative actions. Direct relation of a person to the role behavior in media landscape is expressed in a number of assumptions in the theory of George Herbert Mead. According to him, self-consciousness is the result of social interaction in the course of which an individual perceives oneself as an object. A Man can put oneself in the place of the other and assess oneself from a perspective of this other thus taking his/her role. Meanwhile, the other can be represented by either "the Significant Other" or "the Generalized Other". "The 
Significant Other" exerts influence on socialization of an individual, on forming his values and behavioral models, "an individual becomes who he is by being directed by the significant other" (Berger and Luckmann, 1995). "The Generalized Other" represents an image that exists in social consciousness as a complex of mindsets and expectations with regard to social roles.

Within the structure of personality, Mead distinguishes such components as $\mathrm{Me}$ and $\mathrm{I}$, the aggregate of which forms the integrity of Self. Each of the components has specific features of manifestation in communicative action. Mead identifies individual and collective games as forms of social interaction. In the course of individual game, the social roles are adopted and the social identities are consolidated. The collective or group game is organized and it has definite rules; it makes it possible to learn the whole set of social roles under predefined situations of interaction, to coordinate them, to take into account the motives and the attitudes of all participants. A player has to learn to take the role of the other, to coordinate the positions of others and to coordinate his own position in relation to them (Mead, 1994). Corrections brought about to Mead's theory by modern life consist of the requirements to take into account the faster pace of life and, consequently, the permanent changes in the rules of the game. Collective game with real partners takes place under the conditions predetermined by social landscape, while individual game moves to media landscape where the identity itself becomes its subject and the rules of the game are dictated by the agent of media landscape.

Social game based on actualized Self is played at the level of interpretations, creative understanding of human actions, behavior and activity. It is substantiated by understanding the character, by analysis of the events, by the logic of relations. Heinz Abels defines Self in the sense that Mead attributes to it, namely, as "the ability to look at oneself from the outside", as the identity proper. Taking a role, a human being comprehends himself/herself and exercises control over the process of his/her own communications, i.e., social roles can form only under conditions, in situations and cases of social interaction (Abels, 2000). Everything one person tells the other, he/she also tells oneself. Any characterization of the other is the characterization of one own self (naturally, under the given conditions, in situations and cases of social interaction). It is exactly this feature of hetero- and auto-stereotypization in the process of communication that is necessary for the identity to appear.

Communicative action is focused on achieving mutual understanding and on correlating the role expectations. The structure of communicative action has been described by Habermas (2001). To explain the problem of communication as mutual understanding
Habermas refers to the concept of "Life-world" of Edmund Husserl, who noted that "people of one and the same world either live in quite vague cultural society or do not belong to the same cultural society at all and hence they construct different surrounding worlds of culture as certain life-worlds where absolutely isolated communities live, acting and being acted upon" (Husserl, 2010).

Interrelations between the identity and communicative action are ultimately expressed in the utterance which represents the form of the thought moving toward the word (sign) which has its consequence in the form of difference between facts (self-identity) and reality (designation). Such difference can be found in the ideas of Yu. M. Lotman. He distinguishes two cases of communication: Within the system "I-He" and within the system "I-I" (autocommunication) (Lotman, 1996).

In anthropological sense, the identity implies determining the nature and the image of the living environment, as far as a human being has to perceive and to understand the space where his actions take place. Sociological analysis of social landscape in the living environment refers to social statuses, to the relevant roles with different degrees (depending on the value of the status) of internalization as well as to the practices of social action. Psychological evaluation of role behavior of a person suggests that both external rational status indicators and the internal identifying features of personality should be considered.

\section{Education as an Institution for Creating Media Identity}

The concept of media identity as the ability to perceive oneself as an agent in the media landscape and to correlate one's own communicative actions with the actions of other agents implies referring to a great number of research studies in the sphere of media education. For the purposes of this study, the most important among them are the following: (1) Ideas of L. Masterman about three groups of approaches to media education and to the target media competences, accordingly: Injection approach, media as a type of popular art and media as a representation of the world through the system of symbols (Masterman, 2001); (2) structure of media competences, suggested by Piette and Giroux (2001); (3) a proposition by Aufenganger (1999) to distinguish protective, critical, practical and anthropological functions in media education.

One of the first and the most popular forms of media competence classification is to create a structure in line with the model developed by G. Lasswell within the framework of the communication theory. C. B. Brunner and W. Tally propose five questions, the answers to which will give the idea about the level of a respondent's 
media competence: "How was it created? What values make the basis of it? What conventionalities are used here? For what kind of audience was it intended? Who is the owner of this? Who profits from this?" (Brunner and Tally, 1999). Similarly, the key media competences have been structured by M. Considine and S. Marginson: The source, the structure/organization/owner of the media; the message, contents, values, ideology; the audience; the form, the style, codes, conventionalities, techniques; impact and consequences; objectives, profit, motives (Marginson and Considine, 2000).

A widely applied and largely discussed methodology for determining competences in media among other spheres have been suggested by J. Bloom. This scheme is the one that is frequently applied in Russian media education practice in the course of developing tests and tasks to evaluate media literacy and media competences. J. Bloom suggests that the groups of media competences should be split in blocks by knowledge, understanding, application, analysis, synthesis, evaluation (Huitt, 2001). This scheme is quite useful due its universal character, however, it should be noted that this is the only scheme adopted by media education practice and it is not directly related to this sphere.

\section{Method}

The objective of the study is to identify media identity in the structure of the personality of a graduate pupil from modern Russian secondary school, to determine its meaning for an individual. The graduate pupils of the secondary schools of Saint Petersburg represent the object of the study; the subject of the study is the forms of manifestation of their media identities. The tasks of the study include determining the forms of media behavior and the intensity of media activity in the social group under investigation.

The model of the study has been constructed based on four groups of statements: I can, I am capable of doing it, I know, I know how to do it. General statements representing the model have been applied to compiling the individual question lists, which have been divided in four groups, accordingly. The group of statements "I can" helps estimating the theoretical possibility to work with the information, accessibility of this information and the technical means to forward it. The group of the statements "I am capable of doing it" describes basic skills mostly associated with the experience in interacting with media; development of these skills is related not only to the sphere of education but also to the sphere of social experience in general. A group of competences "I know" characterizes theoretical and practical knowledge of a person in the sphere of working with media, it helps describing the degree of awareness and reflectivity of his actions. The group "I know how to do it" reflects practical skills of an individual in the sphere of working with media.

The model of sample population in this study has been stipulated by the types of specialized education of the graduates: The survey covered the pupils of physics and mathematics lyceum, the pupils of Liberal Arts College and the pupils of comprehensive school.

Within the framework of this study, basic data have been obtained by means of questionnaire survey. A questionnaire consisted of both open-ended and yes-no questions. The study also employed the methods of experiment when the respondents were asked to provide comments on a real media message, as well as the method of media charts when the respondents were given the opportunity to formulate the hierarchy of actual events, to identify major participants of media process in their personal opinions. The results were processed in two stages: the first stage included data transfer to the program for statistical data processing and for developing the coding method appropriate for this particular study, the second stage covered the analysis of the processed data in accordance with the proposed model of media identity.

\section{Results}

\section{Information Consumption}

The frequency of contacts with this or another type of media predetermines the potential non-technical possibility to receive media message and it implies either presence or absence of probability to receive media texts of certain types. Internet is the most authoritative and widely used source of information for all the respondents. Thus, the level of contact competence in the sphere of Internet media texts was the highest for all participants.

The pupils of the physics and mathematics lyceum read press more often than other pupils ( $16 \%$ do it every day while in other schools this figure makes 10\%). The pupils of the liberal arts college exclude contacts with press completely more often as compared to other respondents: $44 \%$ of them have never read periodical publications, while the pupils from the comprehensive school gave similar answer in $21 \%$ of cases and those from the school of physics and mathematics did so in $10 \%$ of cases.

Modern youth still watches TV, the answers "I don't watch" have been received just in $5 \%$ of cases in the comprehensive school and in $14 \%$ of cases in the physics and mathematics lyceum. The consumption of television media texts is affected by educational profile: TV is watched every day by $33 \%$ of the respondents from the physics and mathematics school, $39 \%$ of the respondents from the liberal arts school and $46 \%$ of the respondents from the comprehensive school. Contact competence at 
the level of finding TV media texts is higher among the graduates from the comprehensive school as compared to the respondents from other schools.

The choice of mass media source results from the experience in interacting with this or another source and it includes capability to classify the sources depending on the desired information. The pupils from the physics and mathematics school, notwithstanding the fact that their contacts with press are more frequent, do it intermittently: $76 \%$ of them do not have any favorite publishing house, scientific and research publications were named among their favorite mass media sources in $22 \%$ cases. $41 \%$ of the liberal arts school pupils could name their favorite publishing house and this ratio is the highest as compared to other schools. The pupils from the comprehensive school do not give preference to any particular source more often as compared to other schools $(80 \%)$. Motivation competence at the stage of searching for media texts in press is better developed in the liberal arts college, while the pupils from the comprehensive school reveal the lowest level of this competence.

In $72 \%$ of cases the pupils from the physics and mathematics school do not have a favorite TV channel, $10 \%$ named an entertainment channel $(2 \times 2$ or STS $)$, in $11 \%$ of cases they mentioned the federal news channels (ORT and Russia 24), 9\% named popular science channels (Discovery and Kultura). Among the pupils from the liberal arts school, the preferences were divided as follows: $20 \%$ did not have any favorite channel, $44 \%$ preferred entertainment channels, $27 \%$ named the federal news. The pupils from the comprehensive school do not have any favorite channel in a half of cases, $32 \%$ prefer entertainment TV channels, $10 \%$ like educational channels. The pupils from the liberal arts school give preference to the news information (53\%) and to entertaining series $(55 \%)$, while the pupils from the physics and mathematics school prefer the news in most cases (72\%). Among the pupils from the comprehensive school, the series have a strong lead $(83 \%)$.

In $65 \%$ of cases, the graduates from the physics and mathematics school cannot imagine a situation when their information choices would change. However, $22 \%$ do admit that they would change their selected source of mass media as a result of some important event, $13 \%$ would change the source of mass media in their search for new knowledge and if they had enough leisure. The pupils from the liberal arts school proved to be more flexible: $44 \%$ of those who had a favorite mass media source could imagine shifting to another source if they moved to another place, if this source became boring or if another media was recommended by an authoritative person. The pupils from the comprehensive school change their mass media habits with greater ease: Half of them imagine such a situation very well and $36 \%$ of the respondents associate such a change with the importance of a media event (usually expressed in headlines and trailers). For $5 \%$ of the respondents, changing the mass media priorities represents a possibility to look at an event from a different angle.

As regards topical priorities of the pupils from the comprehensive and from the physics and mathematics schools, science occupies the leading position (56 and $65 \%$ correspondingly), while the pupils from the liberal arts school prefer adventures (55\%). The next popular topics with the respondents are sports and politics. Erotica is popular among all the respondents: It has been marked as one of the most interesting topics by $41 \%$ of the respondents from the physics and mathematics school, by $39 \%$ of the respondents from the comprehensive school and by $30 \%$ of pupils from the liberal arts school (this relatively low level can be explained by the fact that $80 \%$ of the pupils are girls).

Consumption of information is a common communicative action for all groups of media users. Television and radio have actually interlinked with network media, acquiring advantages and disadvantages inherent in the latter. Consumer advantages include the accessibility of information and its technical qualities-the image and sound, the possibility of copying and duplicating. The disadvantages for consumer are the need to orientate in the vast arrays of information and potential controllability of media behavior and drawbacks for the media business include poorly controlled and little managed fractionation of media audiences (i.e., the target audiences of consumers of the advertised goods and services) due to the large number of media offers.

Television is used as a means of appeal to a mass audience; television identity is formed at the sites of interest related to the implementation of entertainment and, more rarely, educational functions by mass media.

Specific functions are assigned to radio and periodicals consisting in the work with reference groups of opinion leaders and with audiences, preserving the habits of consuming print and radio media. The disappearance of the periodical press as a channel of information is associated with the loss of reading practice and, accordingly, with the termination of the reproduction of the reading audience.

\section{Communication}

Network resources are used as communication tools; it is a communication in the social networks that formation of media identity is linked to in the younger audience groups.

Ultimate leadership among the pupils of all schools belongs to social network VKontakte [vk.com] (100\% of the respondents from the physics and mathematics school, $95 \%$ of the respondents from the comprehensive 
school and $90 \%$ of the respondents from the liberal arts school). The majority of respondents use social networks as an aggregator of multimedia content. As a rule, the pupils are aware of the fact that watching films on the Internet may be unlawful: In the liberal arts school, the largest number of pupils are sure of this $(80 \%)$, in the physics and mathematics school $55 \%$ of the respondents believe this is true, in the comprehensive school $40 \%$ think so. The pupils who are sure that this is not a violation of law made $10 \%$ in the liberal arts school, $25 \%$ in the physics and mathematics school and $30 \%$ in the comprehensive school.

The respondents from the liberal arts school are the most active generators of media messages in social networks. $20 \%$ undertake some sort of activity several times per day, one third of them do so several times per week. The pupils from the comprehensive and the physics and mathematics school are somewhat less active. Among them, the most popular answer was "several times per month". The contact competence at the stage of information transfer is much better developed among the pupils from the liberal arts school.

The identity model, determined by the need for selfknowledge and self-determination promotes popularity of social networking among schoolers. Identification of communication occurs, firstly, as taking the role of interlocutor with respect to the participants in the discussion (multiplayer game), secondly, as the acceptance of the desired role (orientation), expressed as the network name (nickname) and profile image (avatar) (individual game). In the second case media identity no longer complements the existing identities (age, sex, education profile, living area, hobby), but replaces them.

\section{Creativity}

In the physics and mathematics school $20 \%$ of pupils had an experience of creating media and the same figure was obtained in the comprehensive school, while in the liberal arts school such cases amounted to just $8 \%$. The most popular form of creating media proved to be a website; the respondents from all three schools had an experience in creating such type of media product. In the liberal arts school and in the comprehensive school, creating a website content was the only type of activity of this kind, while the respondents from the physics and mathematics school also took part in releasing a magazine and a radio program. Obviously, the stage of information generation with all relevant indicators of competences is underdeveloped.

Creative type of media identity among young people is not identified also due to a critical attitude to their own works and low self-esteem compared to the samples ("The Significant Other"). Author's creativity is stimulated by the teachers, it often takes the form of class and social assignments, i.e., is not supported by the internal attitudes of the learner.

The level of media competences among the respondents is to a very small degree dependent on the type of the educational institution attended by these respondents. Within the framework of this study, no strong correlations were discovered except the evident direct dependency of the favorite media channel and favorite mass media source on the school profile and the better developed skill in the formal text analysis among the graduates of the liberal arts school. It can be maintained that at this level of abstraction the age group under study should be considered as an identical community.

The investigation makes it possible to discuss the establishment of a new concept for evaluating the level of media competence that can be characterized as an integral model and can be applied to conducting investigations in this sphere on a larger scale. Modern teenagers are in need of media educational courses at school. Expectedly, they do possess good practical competences, which give the impression of their capable media activities. However, the results obtained when the respondents answered the questions pertaining fundamental and theoretical issues of interacting with media, make it possible to maintain that the competences in this sphere are insufficient. Such incompetence is an important factor, as anyone can become a producer of media.

\section{Discussion}

The issue of pressing concern in the context of the undertaken investigation is to determine the quality and typology of the agents in media landscape. Based on the existing typology of agents, S. I. Shelonaev suggests that a role analysis should be applied. He distinguishes several groups of media landscape agents: Creators (bearers of social interests affecting collective consciousness), journalists (they realize their creative, professional and personal economic interests), owners of mass media (they realize their business interests), mass audience (they receive information to be oriented in the living environment). In this context, the division between journalists and creators is of role-based nature, journalists act as translators simultaneously realizing the complex of interests of their own. One of the researchers provides clarifications that "the true understanding should be searched for on the ways of analyzing the positions and professional roles of creators and journalists in the field structure of media landscape. Indeed, in practice we see that the creators, professionals in some certain spheres, are continuously involved in the media landscape. A number of creators are directly interested in being included into the media landscape in 
order to directly affect the mass consciousness, to promote themselves and their ideas. At the same time, other famous journalists begin positioning themselves in the media landscape as historians, economists, political experts, etc." (Shelonaev, 2011).

With all respect to the role-based approach advocated by S. I. Shelonaev, determining the translating group of agents as journalists does not seem very appropriate. As regards the principles of establishing the typology, the authors suggest that the dominating type of social action should be applied based on which the relevant groups of social roles should be distinguished: Authors, communicators, navigators and addressees (Blokhin, 2012).

Social action is a result of performing a social role that corresponds to the social status of a personality. The role is a projection of the social status of an individual. Inasmuch as the role represents a pattern of expected behavior, its attributes are associated with social stereotypes of the bearers of such expectations. Indirect communicative action is considered an elementary unit of media landscape. In the course of this action, a person acquires the properties of the text, presents himself/herself as a text. The oneness of the text and the man is stipulated by their common symbolic nature: The existence of a human being is covered by such symbols as a status, a social action performed, speech and written texts, external attributes and movements.

As the sector of media landscape grows continuously within the social space, the direct communicative social action is replaced by the indirect one. The possibility of performing the roles that are not associated with particular status results in the uncertainty of role expectations and in the larger communicational freedom of personality in the media landscape. The authors of a monograph titled "Freedom of Personality in Mass Communication" suggest that communication freedom should be studied as the property of an individual himself/herself that ensures his/her independence from social roles and stereotypes dictated by mass media, as an intellectual ability to provide interpretations, ability to reach the post-conventional level of communications (Korkonosenko et al., 2010).

\section{Conclusion}

Results of the study prove that in the youth audience the media identity is formed as the adoption of a social role of one or more agents of the media space. These agents include a recipient (the information consumer), a communicator (the communication initiator) and an author (the media work creator).

The most natural form of communicative action is represented by consumption of information. It should be regarded as the beginning of the feedback relation within the communication system. In ontological sense, the consumer of information demonstrates the sameness of the subject and the object of interaction; the mechanism of this sameness consists of identification, the process when the consumer takes the role that is prescribed and predetermined by the message. Identification is for the consumer a means of imbibing mindsets and values suggested by the message as his/her own mindsets and values.

The second form of communicative action is communication proper that predetermines the type of communicators. Their functions cover initiating and producing messages. The activity of communicators results in establishing the network structures similar to social structures. The networks emerge based on objective needs for communication with the purposes of solving certain (definite) tasks. Within the network community, media identity is formed in the hubs of activity. Specific function of the communicator is represented by mediatization of private life. It is founded on the postulate of the freedom to expose privacy. An individual is requested, at least, to acquiesce to this state of affairs when the exposure of privacy (turning everyday life into a media event) becomes one of the bases of media identity.

Media identity of the author-creator, of the producer of information, who turns his/her routine life into the event and who needs to do so, leads to creating another reality, governed by certain conditions "from the prospective of which the conventional way of life looks like real reality" (Luhmann, 2005).

Communicative action in media landscape can also be manifested in the form of navigation. The task of a navigator is to regulate and to route the torrents of information. His functions, among others, include control over consumption, communication and creative activity. Depending on the objectives of navigation, he/she either helps or creates obstacles for certain relevant agents of media landscape. The nature of the navigator's activity makes it possible to distinguish different types of navigation as follows: Propagating information through information and advertising agencies, distributing mass media sources, regulating (stimulating, arranging or banning) information and communication, deleting or damaging information (hacking), etc. Media navigation as a means for strengthening media identity is facilitated by professional specialization and, consequently, by the formation of social and professional roles. Due to specialization, this type of media identity cannot be identified at the level of pre-professional education.

The stimuli for establishing media identity in the network environment are represented by the factors that predetermine its specific features and are simultaneously the factors of attracting an addressee: Multimedia 
character, hypertextuality and interactivity. Multimedia character, for example, reveals itself as a feature of "extension" of a person, his/her desire to enhance the scope of his/her comprehension. However, the technology remains just a tool for organizing both social and media landscape by means of forming interactive environments and by means of exercising control over hypertextuality. These new requirements make it necessary for an author to possess the required competences, to perceive the hints and nuances, to determine contexts and to control impressions.

The risks related to the growing importance of media identity in personal self-determination of a person are associated with the increased amounts of information and growing intensity of communications. A person acting in the media landscape is required to possess regulative power of self-regulation in consuming the information and self-control in the course of communication. Under the conditions of mediatization, the choice of the degree of openness (media accessibility) becomes inevitable. A failure to organize oneself and the reluctance to break free results in insufficient amount of personal time and in alienation from the results and the process of one's own labor, from community and from one's own self. The risk of alienation contributes to self-imposed refusal from freedom, acquiescence to restrictions and media control. Media landscape provides a person with technological advantages of interactivity (both with the communicators and with the gadgets) and multimedia to enhance opportunities for personal development. Resisting the temptation of media is only possible when an informed solution is made as regards self-determination in the media landscape stipulating the use of its advantages for solving social problems of modern society and for harmonious development of personality. Social functions of media landscape open prospects for solving the issues associated with bureaucracy, transport, communications, security, delivering information to the population. For the purposes of developing personality, media landscape provides access to education and cultural values, opens organizations and territories.

\section{Acknowledgement}

The authors are grateful to Ekaterina Vladimirovna Kasumova for organizing and processing the results of the investigation and to Administrations of Physics and Mathematics Lyceum No. 239, Liberal Art College No. 610 and Comprehensive School No. 150 in Saint Petersburg for their assistance in conducting the survey.

\section{Author's Contributions}

All the authors have contributed equally to conducting the survey and writing of the article.

\section{Ethics}

This article is original and contains unpublished material. The corresponding author confirms that all of the other authors have read and approved the manuscript and there are no ethical issues involved.

\section{References}

Abels, H., 2000. Interaktsiya, Identichnost, Prezentatsiya: Vvedenie v Interpretativnuyu Sotsiologiyu [Interaction, Identity, Presentation: Introduction to Interpretative theory of Sociology]. Aleteya, St. Petersburg.

Aufenganger, S., 1999. Lernen mit den neuen Medien: Perspektiven für Erziehung und Unterricht. MedienGeneration: Beiträge zum 16. Kongress der Deutschen Gesellschaft für Erziehungswissenschaft, Gogolin, Ingrid/Lenzen, Opladen, pp: 61-76.

Berger, P. and T. Luckmann, 1995. Sotsialnoye Konstruirovanie Realnosti: Traktat po Sociologii Znaniya [Social Construction of Reality: A Treatise on Sociology of Knowledge]. 1st Edn., AcademiaCenter, Medium, Moscow.

Blokhin, I.N., 2012. Grazhdanin Mediapolisa [A Citizen of Mediapolis]. Sovremennyiy rossijskiy mediapolis [Modern Russian Mediapolis]. SPbGU, St. Petersburg, pp: 221-226.

Brunner, C. and W. Tally, 1999. The new Media Literacy Handbook: An Educator's Guide to Bringing new Media into the Classroom. 1st Edn., Anchor Books, New York, ISBN-10: 0385496141, pp: 228.

Cooley, C.H., 2000. Chelovecheskaya Priroda i Sotsialniy Poryadok [Human Nature and the Social Order]. 1st Edn., Ideya-Press, Moscow.

Ericson, E., 2006. Identichnost: Yunost i krizis [Identity: Youth and Crisis]. 1st Edn., MPSI: Progress, Moscow, Flinta.

James, W., 1991. Psychology. 1st Edn., Pedagogika, Moscow.

Habermas, J., 2001. Moralnoye soznanie i kommunikativnoe deystvie [Moral consciousness and communicative action]. Nauka, St. Petersburg.

Huitt, W., 2001. Bloom et al.'s taxonomy of the cognitive domain. Educational Psychology Interactive. Valdosta State University, Valdosta.

Husserl, E., 2010. Kartezianskie meditatsii [Cartesian Meditations]. Akademicheskiy Proekt, Moscow.

Korkonosenko, S.G., M.E. Kudryavtseva and P.A. Slutskiy, 2010. Svoboda lichnosti v massovoy kommunikatsii [Personal Freedom in Mass Communication]. SPbGETU "LETI", St. Petersburg. 
Lotman, J.M., 1996. Vnutri mislyashikh mirov. Chelovek-tekst-semiosfera-istoriya [Inside of Thinking Worlds. Person-Text-SemiosphereHistory]. Yaziki Russkoy Kulturi, Moscow.

Luhmann, N., 2005. Realnost Massmedia [The reality of mass media]. Praksis, Moscow.

Marginson, S. and M. Considine, 2000. The Enterprise University: Power, Governance and reinvention in Australia. 1st Edn., Cambridge University Press, Cambridge, ISBN-10: 052179448X, pp: 272.

Masterman, L., 2001. A Rationale for Media Education. In: Media Literacy in the Information Age: Current Perspectives, Kubey, R. (Ed.), Transaction Publishers, New Jersey, ISBN-10: 0765808544, pp: 15-78.
Mead, G., 1994. Az i Ya [Elementaries]. Amerikanskaya sociologicheskaya mysl: Teksty [American sociological thought: Texts]. MGU, Moscow.

Piette, J. and L. Giroux, 2001. The Theoretical Foundation of Media Education Programs. In: Media Literacy in the Information Age: Current Perspectives, Kubey, R. (Ed.), Transaction Publishers, New Jersey, ISBN-10: 0765808544, pp. 89-134.

Shelonaev, S.I., 2011. Mediaprostranstvo: Struktura i raspredelenie sotsialnogo kapitala media-agentov [Media Space: The Structure and Distribution of Social Capital of Media Agents]. Terra Humana, 4: 81-85. 